\title{
Controle de superbrotamento e produtividade de alho vernalizado sob estresse hídrico
}

\author{
Fábio Silva Macêdo(1) ${ }^{\text {Rovilson José de Souza }}{ }^{(1)}$ e Geraldo Magela Pereira(2)
}

(1)Universidade Federal de Lavras (Ufla), Dep. de Agricultura, Caixa Postal 37, CEP 37200-000 Lavras, MG. E-mail: fsmacedo@yahoo.com.br, rovilson@ufla.br (2)Ufla, Dep. de Engenharia. E-mail: geraldop@ufla.br

\begin{abstract}
Resumo - O objetivo deste trabalho foi determinar a influência do deficit hídrico, aplicado em diferentes épocas e períodos sem irrigação, na incidência do superbrotamento e na produtividade de alho nobre vernalizado, cultivar Roxo Pérola de Caçador. O experimento foi conduzido em condições de campo, utilizando-se o delineamento de blocos casualizados, com três repetições. Utilizou-se o esquema fatorial $4 \times 4+1$, com quatro épocas de suspensão da irrigação (aos 50, 55, 60 e 65 dias após o plantio), quatro períodos de deficit hídrico (8, 12, 16 e 20 dias), e um tratamento controle, não submetido ao deficit hídrico. Os bulbos-semente foram submetidos à vernalização de 50 dias a $4^{\circ} \mathrm{C}$. O aumento no período de deficit hídrico, em todas as épocas, possibilitou redução linear nas taxas de superbrotamento, permitindo incremento linear na produção de bulbos comerciais. Maiores períodos de deficit hídrico favorecem a obtenção de bulbos comerciais com maior massa média.
\end{abstract}

Termos para indexação: Allium sativum, irrigação, bulbificação.

\section{Control of secondary bulb growth and productivity of vernalized garlic under water stress}

\begin{abstract}
The objective of this work was to verify the effect of the water deficit, applied in different times and periods without irrigation, in the incidence of the secondary bulb growth and in the yield of noble vernalized garlic, cultivar "Roxo Pérola de Caçador". The experiment was conducted under field conditions, using the experimental design of randomized blocks, with three replications. The factorial scheme used was $4 \times 4+1$, with four irrigation suspension times (at the 50,55, 60 and 65 days after planting), four periods of water deficit (8, 12, 16 and 20 days), and one control treatment, not submitted to water deficit. The bulbs used for planting were submitted to the vernalization of 50 days at $4^{\circ} \mathrm{C}$. The increase in the period of water deficit in all times reduced linearly the secondary bulb growth taxes, with linear increment in the production of commercial bulbs. Larger periods of water deficit favor the obtainment of commercial bulbs with larger medium mass.
\end{abstract}

Index terms: Allium sativum, irrigation, bulbification.

\section{Introdução}

A presença de anormalidades fisiológicas em alho é um dos fatores que mais causam redução na produtividade. O superbrotamento é uma anomalia de causas genético-fisiológicas caracterizada pela brotação antecipada dos bulbilhos, antes da colheita. É uma característica que influi negativamente na cultura do alho, pois além de reduzir a produtividade, deprecia o produto, fazendo com que seu valor comercial seja comprometido (Souza \& Casali, 1986).

Diversos fatores têm sido relacionados ao superbrotamento em alho, como fotoperíodo (Park \& Lee, 1979), temperatura (Souza \& Casali, 1986), cultivar (Souza \& Macêdo, 2004), nitrogênio (Büll et al.,
2002), irrigação (Garcia, 1964), e giberelina (Moon \& Lee, 1980).

Em alhos nobres vernalizados, o superbrotamento tem sido motivo de maior preocupação, já que as cultivares geralmente são mais sensíveis a esta anomalia. A prática da vernalização, que consiste em submeter os bulbossemente a baixas temperaturas por um determinado período, visando a reduzir a exigência destas cultivares ao fotoperíodo e à temperatura, também pode interferir na ocorrência do superbrotamento. Segundo Burba (1983), a vernalização dos bulbilhos estimula o acúmulo de citocininas e giberelinas, modificando o balanço hormonal e levando o bulbilho à brotação precoce.

A disponibilidade de água para as plantas de alho é um fator de grande importância, para a obtenção de uma 
boa produtividade (Souza \& Casali, 1986). Entretanto, resultados obtidos por Garcia (1964) mostram que o teor de água a ser disponibilizado no solo para a cultura está relacionado com a cultivar empregada. Com um teor de água disponível de $90 \%$ e suspensão da irrigação 10 dias antes da colheita, a cultivar Lavínia apresenta boa produtividade, com baixo índice de superbrotamento. Nessas condições, a cultivar Branco Mineiro apresenta baixo desempenho produtivo e alta incidência de superbrotamento e, para esta cultivar, indica-se o teor de água disponível de $60 \%$ e suspensão da irrigação 25 dias antes da colheita.

Uma das alternativas utilizadas por alicultores, visando a reduzir a incidência de superbrotamento, consiste na suspensão da irrigação durante o período de bulbificação, provocando um deficit hídrico. De acordo com Souza et al. (2001), uma das primeiras respostas das plantas à deficiência hídrica é o fechamento dos estômatos, e com isto, há diminuição da difusão de $\mathrm{CO}_{2}$ para o mesófilo foliar, o que causa a queda na fotossíntese.

Segundo Bermúdez-Zambrano (2004), o ácido abscísico (ABA) é o hormônio envolvido nos processos fisiológicos quando as plantas são expostas a alguns tipos de estresse, como deficiência hídrica. Relativamente grandes quantidades de ABA são rapidamente sintetizadas nas folhas em resposta ao estresse hídrico, cujo principal papel está relacionado à regulação da abertura e fechamento estomático. De acordo com Moon \& Lee (1980), a formação dos bulbos em alho está relacionada à alta atividade de ABA, ao passo que as giberelinas seriam o fator endógeno responsável pelo superbrotamento. A maior síntese de ABA possivelmente interfere no balanço hormonal das plantas, diminuindo a atividade das giberelinas e, conseqüentemente, reduzindo a incidência de plantas com superbrotamento.

De acordo com Casagrande et al. (2001), o efeito da deficiência hídrica na produção de determinada cultura depende da época de ocorrência e de sua severidade. Além disso, segundo Amaral et al. (2003), materiais com diferentes genótipos em uma mesma espécie podem responder de maneiras distintas ao estresse causado pela deficiência hídrica.

O objetivo deste trabalho foi avaliar o comportamento produtivo e a ocorrência de superbrotamento em alho vernalizado, cultivar Roxo Pérola de Caçador, submetido a deficit hídrico em diferentes épocas e períodos sem irrigação.

\section{Material e Métodos}

O experimento foi conduzido em condições de campo no setor de Olericultura da Universidade Federal de Lavras (Ufla), no período de 26 de abril a 26 de agosto de 2004. A Ufla situa-se no Município de Lavras, sul de Minas Gerais, a uma altitude média de $910 \mathrm{~m}$, a 211ㄴ'S e $45^{\circ} 0^{\prime} \mathrm{W}$. O clima da região, segundo a classificação de Köppen, é do tipo Cwb, caracterizado por uma estação seca entre abril e setembro e uma estação chuvosa de outubro a março. A região apresenta média anual de precipitação pluvial de 1.493,2 mm e temperatura de 19,3ㄷ (Brasil, 1992).

O experimento foi implantado em Latossolo Vermelho distroférrico (Embrapa, 1999). Amostras de solo da camada de 0-20 cm foram coletadas para determinação da curva característica da água do solo e para análises físicas e químicas. A análise química do solo mostrou os seguintes resultados: $\mathrm{pH} \mathrm{H}_{2} \mathrm{O}, 5,2$; $\mathrm{P}$ disponível (extrator Mehlich 1), 10,4 $\mathrm{mg} \mathrm{dm}^{-3}$; K disponível, $89 \mathrm{mg} \mathrm{dm}^{-3} ; \mathrm{Ca}^{2+}, 2,6 \mathrm{cmol}_{\mathrm{C}} \mathrm{dm}^{-3} ; \mathrm{Mg}^{2+}, 1,1 \mathrm{cmol}_{\mathrm{C}} \mathrm{dm}^{-3}$; $\mathrm{Al}^{3+}, 0,0 \mathrm{cmol}_{\mathrm{C}} \mathrm{dm}^{-3} ; \mathrm{H}+\mathrm{Al}^{3+}, 4,5 \mathrm{cmol}_{\mathrm{C}} \mathrm{dm}^{-3} ; \mathrm{SB}$, 3,9 $\mathrm{cmol}_{\mathrm{C}} \mathrm{dm}^{-3}$; t, 3,9 $\mathrm{cmol}_{\mathrm{C}} \mathrm{dm}^{-3}$; T, 8,4 $\mathrm{cmol}_{\mathrm{C}} \mathrm{dm}^{-3}$; V, 46,6\%; MO, 2,5 dag kg-1; e P remanescente, $11,2 \mathrm{mg} \mathrm{L}^{-1}$. De acordo com a análise física, o solo enquadrou-se na classe textural argilosa.

$\mathrm{O}$ experimento foi montado em esquema fatorial $4 \times 4+1$, consistindo de quatro épocas em que a irrigação foi suspensa (50, 55 e 60 e 65 dias após o plantio) e quatro períodos de deficit hídrico (8, 12, 16 e 20 dias), mais um tratamento adicional, que não foi submetido ao deficit hídrico (controle), totalizando 17 tratamentos. Foi utilizado o delineamento de blocos ao acaso, com três repetições. As parcelas foram dispostas em canteiros com $1 \mathrm{~m}$ de largura, e cada parcela ocupou $2 \mathrm{~m}$ em comprimento do canteiro, totalizando uma área de $2 \mathrm{~m}^{2}$. Cada parcela foi constituída por cinco linhas de plantio espaçadas em 0,2 m. Em cada linha de plantio, foram plantados 20 bulbilhos, espaçados em $0,1 \mathrm{~m}$, totalizando 100 bulbilhos por parcela. Na coleta de dados, foram consideradas três linhas centrais, desprezando-se $0,5 \mathrm{~m}$ das extremidades de cada linha.

A cultivar empregada foi a Roxo Pérola de Caçador, que pertence ao grupo dos alhos nobres e é uma das mais cultivadas em Minas Gerais. Os bulbos-semente foram submetidos ao processo de vernalização em préplantio, sendo colocados em câmara fria com temperatura média de $4^{\circ} \mathrm{C}$, por 50 dias. Os bulbilhos foram classificados em peneiras por tamanho, de acordo com a 
portaria no 242, de 17/9/1992, do Ministério da Agricultura Pecuária e Abastecimento, utilizando-se, para plantio, bulbilhos retidos na peneira 3 (malha de 8x17 mm).

A adubação de plantio consistiu da aplicação de $20 \mathrm{~kg} \mathrm{ha}^{-1}$ de $\mathrm{N}, 200 \mathrm{~kg} \mathrm{ha}^{-1}$ de $_{2} \mathrm{O}_{5}, 60 \mathrm{~kg} \mathrm{ha}^{-1} \mathrm{de} \mathrm{K}_{2} \mathrm{O}$, 4,5 $\mathrm{kg} \mathrm{ha}^{-1}$ de Mg, $3 \mathrm{~kg} \mathrm{ha}^{-1}$ de B e $3 \mathrm{~kg} \mathrm{ha}^{-1}$ de Zn, nas formas de sulfato de amônio, superfosfato simples, cloreto de potássio, sulfato de magnésio, bórax e sulfato de zinco, respectivamente. A adubação de cobertura foi realizada aos 90 dias depois do plantio com $40 \mathrm{~kg} \mathrm{ha}^{-1}$ de $\mathrm{N}$, na forma de uréia. A necessidade de calagem foi calculada pelo método de saturação por bases, sendo a calagem efetuada procurando-se elevar a saturação por bases para $70 \%$, de acordo com recomendação de Souza et al. (1999).

Durante a condução do experimento foram observadas doenças como ferrugem e mancha-púrpura, que foram controladas com pulverizações de produtos à base de Mancozeb, Tebuconazole e Thiophanate-methyl. Pragas que ocorreram no experimento, como tripes e ácaros, foram combatidas por meio de pulverizações com produtos à base de Methamidophos e Chlorphenapyr. O controle das plantas daninhas foi efetuado com capina manual.

A irrigação do experimento até os 50 dias depois do plantio e depois do período de deficit hídrico, nos tratamentos, foi efetuada por meio do sistema de irrigação por aspersão convencional, utilizando-se duas linhas laterais espaçadas em 12 m, com aspersores (bocal de 3,8x3,8 mm) também espaçados em $12 \mathrm{~m}$. A determinação da intensidade de precipitação dos aspersores instalados foi feita seguindose o método descrito por Bernardo (1995).

A fim de realizar o monitoramento da umidade do solo durante a condução do experimento, foram instalados três tensiômetros a $15 \mathrm{~cm}$ de profundidade e dois a $30 \mathrm{~cm}$ de profundidade, em cada parcela do tratamento que não foi submetido a deficit hídrico (controle), para a determinação da tensão da água no solo. As leituras nos tensiômetros foram efetuadas às 8h, diariamente, utilizando-se tensímetro de punção. As irrigações foram realizadas sempre que a média da tensão, obtida por meio da leitura dos tensiômetros instalados a $15 \mathrm{~cm}$ de profundidade, atingia $45 \mathrm{kPa}$, considerando-se que, acima dessa tensão, a umidade do solo é crítica para a cultura (Silva et al., 1981). A lâmina de água aplicada em cada irrigação foi a suficiente para repor o teor de umidade do solo para a capacidade de campo, que, de acordo com Carvalho et al. (1996), é atingida na tensão de $10 \mathrm{kPa}$, para o tipo de solo utilizado neste trabalho.
Com a utilização do modelo proposto por Van Genuchten (1980) e observando-se o comportamento da umidade do solo em função da tensão de água no solo, gerou-se a seguinte equação $\left(r^{2}=0,982\right)$, que representa a curva de retenção de água no solo:

$$
\theta=0,199+\frac{0,301}{\left[1+(0,062 \psi)^{1,3807}\right]^{0,2757}},
$$

em que $\theta$ é a umidade atual, $\mathrm{cm}^{3} \mathrm{~cm}^{-3}$; e $\psi$ é a tensão de água no solo, cca. A partir dessa equação, determinou-se a umidade do solo na capacidade de campo $\left(\theta_{\text {cc }}=0,3461 \mathrm{~cm}^{3} \mathrm{~cm}^{-3}\right)$ e a umidade no momento de irrigar $\left(\theta_{\text {crítica }}=0,2835 \mathrm{~cm}^{3} \mathrm{~cm}^{-3}\right)$, tornando possível a determinação da lâmina de irrigação a ser aplicada.

A irrigação das parcelas dos tratamentos submetidos ao deficit hídrico foi suspensa nas épocas determinadas, pelos diferentes períodos avaliados. Às vésperas da suspensão da irrigação, controlou-se a lâmina de água aplicada nas parcelas de maneira que, no início do período de deficit hídrico, a tensão de água no solo estivesse próxima de $45 \mathrm{kPa}$, já que acima dessa tensão a umidade do solo é crítica para a cultura, caracterizando o início do deficit hídrico.

A irrigação das parcelas que não estavam sendo submetidas ao deficit hídrico foi realizada manualmente por meio de aspersor em forma de T, construído com tubo de PVC. O tubo acoplado no sentido transversal foi perfurado, e os orifícios resultantes possuíam o mesmo diâmetro. O controle do volume de água (lâmina) aplicado em cada parcela foi realizado utilizando-se tambor graduado, sendo a água conduzida por gravidade até o aspersor através de mangueira. A liberação da água do tambor para a irrigação foi efetuada por meio de registros presentes na saída do tambor e na entrada do aspersor manual.

Ao fim do período de deficit hídrico, em cada tratamento, amostras de solo foram coletadas na profundidade de $0-15 \mathrm{~cm}$, para a determinação da umidade com base em massa, e por conseguinte, do volume (lâmina) de água necessário para elevar a umidade do solo até a capacidade de campo. Depois da elevação da umidade do solo para a capacidade de campo, foram instalados tensiômetros nas parcelas dos tratamentos, em razão da tensão de água no solo não coincidir em todos os tratamentos, neste período.

Terminado o período de deficit hídrico em todos os tratamentos, foi determinada a umidade do solo a $15 \mathrm{~cm}$ de profundidade, com base em massa, em todos os tratamentos do experimento. Com isso, pôde-se igualar a 
umidade dos tratamentos, elevando-as para a capacidade de campo, podendo-se, então, utilizar novamente o sistema de irrigação por aspersão convencional. A última irrigação efetuada no experimento ocorreu 13 dias antes da colheita.

A colheita do experimento foi feita 122 dias depois do plantio, na fase de senescência das plantas, quando estas apresentavam em torno de seis folhas verdes. Depois da colheita, as plantas foram curadas ao sol por três dias. Posteriormente, as plantas foram acondicionadas em galpão e curadas à sombra por 25 dias. Efetuada a cura, foram realizados os toaletes dos bulbos e coletados os dados de produção.

Avaliaram-se as seguintes características: massa total de plantas, produtividade total de bulbos, porcentagem de bulbos com superbrotamento, produtividade de bulbos comerciais, massa média de bulbos comerciais, número médio de bulbilhos em bulbos comerciais e massa média de bulbilhos de bulbos comerciais. Para a determinação da massa total de plantas produzidas e produtividade de bulbos, considerou-se uma área cultivada de $7.000 \mathrm{~m}^{2}$ por hectare.

Os dados foram submetidos à análise de variância, sendo as comparações entre os tratamentos integrantes do esquema fatorial efetuadas por meio de análises de regressão. De acordo com recomendação de Yassin et al. (2002), as comparações dos tratamentos fatoriais com o controle foram feitas utilizando-se o teste de Dunnett a 5\% de probabilidade. Para a realização da análise de variância, os dados de porcentagem de bulbos com superbrotamento foram transformados em arc sen $(\mathrm{P} / 100)^{0,5}$ e os dados de número médio de bulbilhos em bulbos comerciais, em $(x+1)^{0,5}$.

\section{Resultados e Discussão}

As épocas em que a irrigação foi suspensa e os períodos de deficit hídrico não exerceram influência sobre a massa total de plantas produzidas e produtividade total de bulbos. Além disso, não se observaram diferenças significativas entre os tratamentos fatoriais e o tratamento controle, para estas duas características. A massa média observada no experimento, de plantas produzidas, foi de 11,91 t ha-1, sendo a produtividade média de bulbos de 9,76 t ha-1. Existem muitos trabalhos sobre irrigação em alho, mas poucos relacionados a efeitos do estresse hídrico sobre as características de produção da planta (Melo \& Oliveira, 1999).
Nas plantas vasculares, a deficiência hídrica afeta principalmente o aparato estomático, reduzindo as trocas de $\mathrm{CO}_{2}$ e, conseqüentemente, a fotossíntese. No entanto, se a planta é suprida com água antes que a capacidade fotossintética atinja um limite crítico, a recuperação das trocas gasosas é rápida. Geralmente, plantas herbáceas cultivadas toleram maior deficiência hídrica, dependendo da espécie e das condições do local de crescimento (Larcher, 2000).

Observou-se interação significativa entre os dois fatores estudados para a porcentagem de bulbos com superbrotamento, com redução linear na porcentagem de superbrotamento em função do aumento do período de deficit hídrico em todas as épocas avaliadas (Tabela 1). As equações que expressam essa relação nos períodos de 50,55, 60 e 65 dias são, respectivamente: $\mathrm{y}=1,8093 \mathrm{x}+56,437\left(\mathrm{R}^{2}=0,64 * *\right) ; \mathrm{y}=-4,6665 \mathrm{x}$ $+93,426\left(\mathrm{R}^{2}=0,97 * *\right) ; \mathrm{y}=-2,1833 \mathrm{x}+52,373$ $\left(\mathrm{R}^{2}=0,87^{* *}\right)$ e y $=-1,298 \mathrm{x}+31,727\left(\mathrm{R}^{2}=0,58^{* *}\right)$.

Mesmo um estresse hídrico moderado é suficiente para desencadear a síntese de ácido abscísico (Larcher, 2000). De acordo com Moon \& Lee (1980), a formação dos bulbos de alho está mais relacionada à alta atividade do ácido abscísico e a altos teores de açúcares totais, enquanto a alta atividade da giberelina exerce influência na indução do superbrotamento em alho. Essa maior produção de ácido abscísico pode, portanto, estar atuando na inibição da ação da giberelina e possibilitando, com isso, a redução das taxas de superbrotamento.

Tabela 1. Porcentagem de bulbos de alho com superbrotamento e produtividade de bulbos comerciais em função de períodos de deficit hídrico, com início em diferentes épocas de suspensão da irrigação.

\begin{tabular}{cccc}
\hline $\begin{array}{c}\text { Período } \\
(\text { dias })\end{array}$ & Época $^{(1)}$ & $\begin{array}{c}\text { Superbrotamento } \\
(\%)\end{array}$ & $\begin{array}{c}\text { Produtividade de bulbos } \\
\text { comerciais }\left(\mathrm{tha}^{-1}\right)\end{array}$ \\
\hline 8 & 50 DAP & $38,2^{\text {ns }}$ & $5,23^{\text {ns }}$ \\
12 & & $35,7^{\text {ns }}$ & $4,76^{\mathrm{ns}}$ \\
16 & & $36,9^{\text {ns }}$ & $5,63^{\text {ns }}$ \\
20 & $13,7^{*}$ & $7,34^{*}$ \\
\hline 8 & 55 DAP & $58,4^{\text {ns }}$ & $2,96^{\text {ns }}$ \\
12 & & $37,1^{\text {ns }}$ & $4,82^{\text {ns }}$ \\
16 & & $12,6^{*}$ & $7,86^{*}$ \\
20 & & $4,3^{*}$ & $9,15^{*}$ \\
\hline 8 & 60 DAP & $36,5^{\text {ns }}$ & $5,40^{\text {ns }}$ \\
12 & & $21,2^{*}$ & $7,00^{*}$ \\
16 & & $22,7^{*}$ & $6,51^{\text {ns }}$ \\
20 & & $6,8^{*}$ & $9,44^{*}$ \\
\hline 8 & 65 DAP & $18,0^{*}$ & $7,10^{*}$ \\
12 & & $17,6^{*}$ & $7,49^{*}$ \\
16 & & $18,3^{*}$ & $7,48^{*}$ \\
20 & & $0,4^{*}$ & $10,25^{*}$ \\
\hline Controle & & 48,9 & 4,24 \\
\hline
\end{tabular}

(1)DAP: dias após o plantio. ns Não-significativo. *Significativo a 5\% de probabilidade, pelo teste de Dunnett. 
Apesar de haver redução nas taxas de superbrotamento com aumento do período de deficit hídrico em todas as épocas em que a irrigação foi suspensa, observou-se que o índice de ocorrência dessa anormalidade, em alguns tratamentos, não diferiu significativamente do observado no tratamento controle (Tabela 1), mostrando a ineficácia desses tratamentos no controle da anormalidade. Quando o deficit hídrico foi iniciado 50 dias após o plantio (DAP), somente o período de 20 dias sem irrigação possibilitou índice menor de superbrotamento em relação ao tratamento controle. Aos 55 dias após o plantio, apenas os períodos de 16 e 20 dias de deficit hídrico permitiram a obtenção de menores taxas de bulbos com superbrotamento. Quando a irrigação foi suspensa aos 60 dias após o plantio, somente o período de 8 dias de deficit hídrico mostrou-se pouco eficiente no controle do superbrotamento. O início do período de deficit hídrico aos 65 dias após o plantio proporcionou taxas de superbrotamento inferiores à observada no tratamento controle, para todos os períodos de deficit hídrico estudados, mostrando que, quando esta prática foi efetuada mais tardiamente, mesmo menores períodos sem irrigação foram eficientes na redução do superbrotamento. Segundo Castro et al. (1987), as alterações no comportamento vegetal em resposta ao deficit hídrico ocorrem em razão da duração e da severidade do estresse, do estádio de desenvolvimento, do genótipo e da história prévia do estresse.

Com relação à produtividade de bulbos comerciais, ou seja, bulbos com diâmetro acima de $32 \mathrm{~mm}$, sem superbrotamento ou chochamento, verificou-se interação significativa entre os dois fatores estudados. Em todas as épocas avaliadas, à medida que se aumentou o período de deficit hídrico, observou-se aumento linear na produção de bulbos comerciais (Tabela 1). As equações que expressam essa relação nos períodos de 50, 55, 60 e 65 dias são, respectivamente: $\mathrm{y}=0,1797 \mathrm{x}+3,2232$ $\left(\mathrm{R}^{2}=0,68 *\right) ; \mathrm{y}=0,5397 \mathrm{x}-1,3574\left(\mathrm{R}^{2}=0,98 * *\right) ;$ $\mathrm{y}=0,2901 \mathrm{x}+3,0235\left(\mathrm{R}^{2}=0,77^{* *}\right)$ e $\mathrm{y}=0,2358 \mathrm{x}+$ $4,7788\left(\mathrm{R}^{2}=0,70^{* *}\right)$. Esse aumento ocorreu principalmente em virtude da redução linear do superbrotamento, com o aumento do período de deficit hídrico, em todas as épocas avaliadas. De acordo com Souza \& Casali (1986), a sensibilidade de algumas cultivares de alho de ótimas características comerciais a esta anormalidade é um entrave à expansão de áreas de plantio. Além disso, com a ocorrência de distúrbios genético-fisiológicos, o produto obtido torna-se menos competitivo com o alho importado, geralmente de melhor aparência e aceitação comercial.
Atualmente, os produtores em Minas Gerais têm suspendido a irrigação em torno de 50 dias após o plantio por um período de 16 a 20 dias. Comparando-se a produtividade de bulbos comerciais de cada tratamento fatorial com a obtida no tratamento controle (Tabela 1), constata-se que o início do deficit hídrico aos 50 dias após o plantio somente possibilitou maior produtividade de bulbos comerciais quando a irrigação foi suspensa por um período de 20 dias. Aos 55 dias após o plantio, o efeito do deficit hídrico no incremento da produtividade de bulbos comerciais foi observado apenas com os períodos de 16 e 20 dias sem irrigação. Quando a irrigação foi suspensa aos 60 dias após o plantio, por 12 e 20 dias, também se verificou produtividade de bulbos comerciais superior à obtida no tratamento controle. Porém, para esta época, a produtividade de bulbos comerciais submetidos ao período de 16 dias de deficit hídrico não diferiu significativamente da verificada no controle. Isto possivelmente ocorreu em virtude da maior produção de bulbos com diâmetro abaixo do aceitável para comercialização. Entretanto, considerando-se o efeito linear do aumento do período de estresse hídrico no incremento da produtividade de bulbos comercias observado na Tabela 1, verifica-se tendência de maior produtividade quando a irrigação era interrompida aos 60 dias por períodos de 12, 16 e 20 dias. O início do deficit hídrico aos 65 dias após o plantio possibilitou a obtenção de produtividade de bulbos comerciais superior à observada no tratamento controle, em todos os graus de deficit hídrico estudados.

Os períodos de deficit hídrico influíram significativamente na massa média de bulbos comerciais, não havendo influência das épocas de suspensão da irrigação. Observou-se um incremento linear na massa média de bulbos comerciais, com o aumento do período de deficit hídrico (Tabela 2). A equação que expressa essa relação é $y=0,32 x+22,02\left(R^{2}=0,96\right)$. Em plantas não

Tabela 2. Massa média de bulbos comerciais e de bulbilhos de bulbos comerciais de alho em função de períodos de deficit hídrico.

\begin{tabular}{ccc}
\hline $\begin{array}{c}\text { Período } \\
(\text { dias })\end{array}$ & $\begin{array}{c}\text { Massa média de bulbos } \\
\text { comerciais }(\mathrm{g})\end{array}$ & $\begin{array}{c}\text { Massa média de bulbilhos } \\
\text { de bulbos comerciais }(\mathrm{g})\end{array}$ \\
\hline 8 & $24,7^{\mathrm{ns}}$ & $1,99^{\mathrm{ns}}$ \\
12 & $25,9^{\mathrm{ns}}$ & $2,06^{\mathrm{ns}}$ \\
16 & $26,7^{\mathrm{ns}}$ & $2,11^{\mathrm{ns}}$ \\
20 & $28,7^{*}$ & $2,30^{*}$ \\
\hline Controle & 24,9 & 2,08 \\
\hline
\end{tabular}

nsNão-significativo. ${ }^{*}$ Significativo a $5 \%$ de probabilidade, pelo teste de Dunnett. 
verdadeiramente resistentes à seca, a sobrevivência durante períodos secos requer somente um programa apropriado para a produção de sementes resistentes à dessecação ou órgãos perenes especialmente resistentes à dessecação. No caso das geófitas, com o estresse hídrico ocorre maior estoque de assimilados em órgãos subterrâneos como rizomas, tubérculos e bulbos, em relação à parte aérea, sendo que quanto maior a exposição ao deficit hídrico, maior será o favorecimento ao acúmulo de assimilados nestes órgãos (Larcher, 2000). Embora tenha sido observado um aumento linear na massa média de bulbos comerciais com a elevação dos períodos de deficit hídrico, a obtenção de bulbos com maior massa média que a obtida quando não houve suspensão da irrigação no período de bulbificação somente foi possível quando se suspendeu a irrigação por 20 dias (Tabela 2).

Não houve influência dos fatores avaliados sobre o número médio de bulbilhos em bulbos comerciais, não havendo também diferenças significativas entre o número observado nos tratamentos submetidos a deficit hídrico e o observado no tratamento controle. O número médio observado no experimento foi 11,9 bulbilhos por bulbo comercial. A portaria № 242/92, do Ministério da Agricultura, prevê que, para pertencer ao grupo nobre, o alho deve apresentar, entre outras características, no máximo 20 bulbilhos por bulbo. O mercado consumidor de alho prefere bulbos de tamanho maior e com pequeno número de bulbilhos por bulbo, fato importante para a comercialização, quando bulbos com estas características alcançam as cotações mais elevadas (Resende, 1997).

Observou-se influência dos períodos de deficit hídrico sobre a massa média de bulbilhos de bulbos comerciais. À medida que se prolongou o período de suspensão da irrigação, verificou-se aumento linear na massa média de bulbilhos. A equação que expressa essa relação é $y=0,0245 x+1,772\left(R^{2}=0,91\right)$. Este resultado influiu diretamente no incremento da massa média de bulbos comerciais, que apresentou comportamento semelhante quando a cultura foi submetida aos diferentes períodos de deficit hídrico (Tabela 2). Taiz \& Zeiger (2004) relatam que o deficit hídrico moderado também afeta o desenvolvimento do sistema subterrâneo. De acordo com os autores, a expansão foliar é afetada precocemente, quando a absorção de água é reduzida. No entanto, a atividade fotossintética é muito menos atingida. A inibição da expansão foliar reduz o consumo de carbono e energia, e uma proporção maior de assimilados vegetais pode ser distribuída ao sistema subterrâneo.

Na comparação da massa média de bulbilhos de bulbos comerciais, obtida nos tratamentos submetidos a deficit hídrico, com a observada no tratamento controle (Tabela 2), observa-se massa média de bulbilhos de bulbos comerciais superior à do tratamento controle, quando a irrigação foi suspensa por um período de 20 dias, o que não ocorreu nos demais períodos avaliados.

\section{Conclusões}

1. A suspensão da irrigação aos 50, 55, 60 e 65 dias após o plantio, por um período de 8 a 20 dias não interfere na massa total de plantas produzidas e na produção total de bulbos.

2. O aumento no período de deficit hídrico resulta em maior massa média de bulbos comerciais e de seus bulbilhos.

3. As taxas de superbrotamento são reduzidas de forma linear com o aumento do período de deficit hídrico, independentemente da suspensão da irrigação ser efetuada aos 50, 55, 60 ou 65 dias após o plantio, havendo, com isso, incremento linear na produção de bulbos comerciais.

\section{Referências}

AMARAL, S.R. do; LIRA, M. de A.; TABOSA, J.N.; SANTOS, M.V.F. dos; MELLO, A.C.L. de; SANTOS, V.F. dos. Comportamento de linhagens de sorgo forrageiro submetidas a deficit hídrico sob condição controlada. Pesquisa Agropecuária Brasileira, v.38, p.973-979, 2003.

BERMÚDEZ-ZAMBRANO, O.D. Sinalização entre os sistemas radiculares e caulinares em genótipos contrastantes de Lycopersicon sob estresse por deficiência hídrica. 2004. 33p. Dissertação (Mestrado) - Escola Superior de Agricultura Luiz de Queiroz, Piracicaba.

BERNARDO, S. Manual de irrigação. 6.ed. Viçosa: Imprensa Universitária da UFV, 1995. 657p.

BRASIL. Ministério da Agricultura e Reforma Agrária. Departamento Nacional de Meteorologia. Normais climatológicas: 1961-1990. Brasília, 1992. 84p.

BÜLL, L.T.; BERTANI, R.M. de A.; VILLAS BÔAS, R.L.; FERNANDES, D.M. Produção de bulbos e incidência de pseudoperfilhamento na cultura do alho vernalizado em função de adubações potássicas e nitrogenadas. Bragantia, v.61, p.247-255, 2002.

BURBA, J.L. Efeitos do manejo de alho-semente (Allium sativum $\mathrm{L}$.) sobre a dormência, crescimento e produção da 
cultivar Chonan. 1983. 112p. Dissertação (Mestrado) Universidade Federal de Viçosa, Viçosa.

CARVALHO, L.G. de; SAMPAIO, S.C.; SILVA, A.M. da. Determinação da umidade na capacidade de campo in situ de um Latossolo Roxo distrófico. Engenharia Rural, v.7, p.91-97, 1996.

CASAGRANDE, E.C.; FARIAS, J.R.B.; NEUMAIER, N.; OYA, T.; PEDROSO, J.; MARTINS, P.K.; BRETON, M.C.; NEPOMUCENO, A.L. Expressão gênica diferencial durante deficit hídrico em soja. Revista Brasileira de Fisiologia Vegetal, v.13, p.168-184, 2001.

CASTRO, P.R.C.; FERREIRA, S.O.; YAMADA, T. (Ed.). Ecofisiologia da produção agrícola. Piracicaba: Potafos, 1987. 249p.

EMBRAPA. Centro Nacional de Pesquisa de Solos (Rio de Janeiro, RJ). Sistema brasileiro de classificação de solos. Rio de Janeiro, 1999. 412p.

GARCIA, A. Influência da irrigação no crescimento, produção e superbrotamento do alho (Allium sativum L.). 1964. 45p. Dissertação (Mestrado) - Universidade Federal de Viçosa, Viçosa.

LARCHER, W. Ecofisiologia vegetal. São Carlos: Rima, 2000. 531p.

MELO, J.P.L.; OLIVEIRA, A.P. de. Produção de alho em função de diferentes níveis de água e esterco bovino no solo. Horticultura Brasileira, v.17, p.11-15, 1999.

MOON, W.; LEE, B.Y. Influences of short day treatment on the growth and levels of endogenous growth substances in garlic plants (Allium sativum L.). Journal of the Korean Society for Horticultural Science, v.21, p.109-113, 1980.

PARK, Y.B.; LEE, B.Y. Study on the growth and bulb formation of garlic plants (Allium sativum L.). I. The effect of day-length on the bulb formation and secondary growth in 6 cloved garlic plants. Journal of the Korean Society for Horticultural Science, v.20, p.1-4, 1979.

RESENDE, G.M. de. Desempenho de cultivares de alho no Norte de Minas Gerais. Horticultura Brasileira, v.15, p.127-130, 1997.

SILVA, W.L. de C. e; CARRIJO, O.A.; OLIVEIRA, C.A.S.; MENEZES SOBRINHO, J.A. de. Irrigação da cultura do alho no Distrito Federal. Brasília: Embrapa-CNPH, 1981. 36p. (EmbrapaCNPH. Circular técnica, 1).

SOUZA, C.R. de; SOARES, A.M.; REGINA, M. de A. Trocas gasosas de mudas de videira, obtidas por dois porta-enxertos, submetidas à deficiência hídrica. Pesquisa Agropecuária Brasileira, v.36, p.1221-1230, 2001.

SOUZA, R.J. de; CASALI, V.W.D. Pseudoperfilhamento: uma anormalidade genético-fisiológica em alho. Informe Agropecuário, v.12, p.36-41, 1986.

SOUZA, R.J. de; MACÊDO, F.S. Vernalização de cultivares de alho nobre na região de Lavras. Horticultura Brasileira, v.22, p.651654, 2004.

SOUZA, R.J.; PAULA, M.B.; CECÍLIO FILHO, A.B. Alho. In: RIBEIRO, A.C.; GUIMARÃES, P.T.G.; ALVAREZ VENEGAS, V.H. (Ed.). Recomendações para o uso de corretivos e fertilizantes em Minas Gerais: $5^{a}$ aproximação. Viçosa: CFSEMG, 1999. p.178.

TAIZ, L.; ZEIGER, E. Fisiologia vegetal. 3.ed. Porto Alegre: Artmed, 2004. 719p.

VAN GENUCHTEN, M.T.H. A closed-form equation for predicting the hydraulic conductivity of unsaturaded soils. Soil Science Society of American Journal, v.44, p.892-898, 1980.

YASSIN, N.; MORAIS, A.R. de; MUNIZ, J.A. Análise de variância em um experimento fatorial de dois fatores com tratamentos adicionais. Ciência e Agrotecnologia, p.1541-1547, 2002.

Recebido em 28 de abril de 2005 e aprovado em 14 de setembro de 2005 